\title{
Current understanding on micro RNAs and its regulation in response to Mycobacterial infections
}

\author{
Pravin Kumar Singh, Ajay Vir Singh and Devendra Singh Chauhan
}

\begin{abstract}
MicroRNAs (miRNAs) are evolutionarily conserved, naturally abundant, small, regulatory non-coding RNAs that inhibit gene expression at the post-transcriptional level in a sequence-specific manner. Due to involvement in a broad range of biological processes and diseases, miRNAs are now commanding considerable attention. Although much of the focus has been on the role of miRNAs in different types of cancer, recent evidence also points to a critical role of miRNAs in infectious disease, including those of bacterial origin. Now, miRNAs research is exploring rapidly as a new thrust area of biomedical research with relevance to deadly bacterial diseases like Tuberculosis (caused by Mycobacterium tuberculosis). The purpose of this review is to highlight the current developments in area of miRNAs regulation in Mycobacterial diseases; and how this might influence the diagnosis, understanding of disease biology, control and management in the future.
\end{abstract}

Keywords: Micro-RNA, Mycobacterial infection, Tuberculosis, Mycobacterium tuberculosis

\section{Review}

Genomic studies revealed that numerous portions of the human genome do not encode conventional proteincoding genes but encode biologically active non-coding RNA species. With the rapid expansion of small RNA interference techniques over the past decade, it is now clear that many small RNA molecules could regulate gene and protein expression. One class of such small noncoding RNAs is microRNAs (miRNAs), a group of regulatory RNAs of 19-22 nucleotides involved in control of gene expression at the post-transcriptional level [1] thereby acting as RNA interfering (RNAi) molecule. While a wellknown RNAi molecule, small interfering RNA (siRNA), is a small RNA that is artificially synthesized, miRNA exists endogenously in the cell. Therefore, miRNAs represents an innate gene-silencing mechanism in our bodies.

miRNAs were first discovered in 1993 while studying Caenorhabditis elegans [2]. The first miRNA discovered was lin-4 that was found to play a role in the development through a negative effect on lin-14 expression [2]. After seven years (in 2000), let-7, the second miRNA was discovered, again in the C. elegans [3]. In last decade,

\footnotetext{
*Correspondence: devchauhan01@yahoo.co.in

Department of Microbiology \& Molecular Biology, National JALMA Institute for Leprosy \& Other Mycobacterial Diseases, Tajganj, Agra (UP) Pin- 282001,
} India

\section{Biomed Central}

significant advances have been made in miRNA research leading to the discovery of more than 1,500 miRNAs that have been fully characterized (as per miRBase database viewed in Oct, 2012) and the number is expected to grow in the coming years. Recent studies suggest that miRNAs are involved in regulating cell fate (cell death and proliferation), initiation and progression of human cancer, developmental timing and orchestration of antipathogenic responses [4-6].

In view of fact that the miRNAs regulates the expression of a number of genes, the dysregulation miRNAs are being investigated extensively for a number of infectious diseases. Although, early works were focused on the role of miRNAs during viral and parasitic infections [7-9], however in recent past, crucial relevance of miRNAs in the interplay between host and bacteria has been demonstrated [10]. This advancement has now attracted the interest of researcher to dissect the role of miRNAs in most deadly infectious human diseases like Tuberculosis. The genus Mycobacterium includes highly pathogenic species Mycobacterium tuberculosis (causing tuberculosis) and Mycobacterium leprae (causing leprosy) but also opportunists such as $M$. avium, which can also cause disseminated infections in immuno-compromised persons such as AIDS patients [11]. Despite advances in 
modern medicine and diagnostics, TB remains a major challenge to global public health in the $21^{\text {st }}$ century. Approximately one-third of humanity is infected, but only $5-10 \%$ of this population develops active disease, which in 2010 accounted for 8.8 million cases of 1.45 million deaths [12]. Unlike to tuberculosis control, last three decades brought success in leprosy control worldwide but recent emergence of 2,44,796 new cases of leprosy in 2009 challenged both clinicians as well as immunologists, especially in developing countries [13]. Though, interactions between Mycobacteria and its environment have been extensively studied, our knowledge at the RNA level is still very limited. Study on deciphering the role of miRNA in mycobacteial diseases, though started very recently, provided some motivating and interesting facts that need to be exploited in future studies for better understanding of disease biology and in designing the efficient control strategies. In this review, we appraise the recent findings on regulation of host miRNAs in response of Mycobacterial infection and underpin the relevance of miRNAs in Tuberculosis.

\section{Gene structure, biogenesis and basic function of miRNAs}

The genesis of functional miRNAs involves a complex multi-enzyme process leading from long precursor molecules into $\sim 22$ nt long biologically active RNA molecules. miRNAs are transcribed from their own genes scattered in all chromosomes in humans, except for Y chromosome [14]. Most miRNA genes are located in intergenic regions (intergenic miRNAs) almost $>1 \mathrm{~kb}$ away from annotated/predicted genes, although some miRNAs were found in intronic regions, within protein coding-genes or in non-coding genes (intronic miRNAs) [15]. Intergenic miRNAs are transcribed as autonomous units with their own promoter/regulatory region, from RNA Polymerase II or III; about a 50\% of intergenic miRNAs are found in close proximity to other miRNAs, forming extended clusters which are transcribed as single polycistronic unit [16]. Intronic miRNAs, residing within protein coding genes or non-coding genes, seem to be transcriptionally related to the expression of their host gene and processed in consequence of the spliceosome formation [17-19]. Transcription of intergenic miRNAs, controlled by their own promoter, generates several $\mathrm{Kb}$ - long pri-miRNAs with CAP structures and poly(A) tails, which allow its subsequent processing reactions. On the other hand, the transcription of intronic miRNAs underlies the control of their host mRNAs using the same promoter, and involves protein complexes of mRNAs splicing machinery [20].

Genes encoding miRNA are generally transcribed in the nucleus by RNA polymerase II (Pol II) into large primary miRNA transcripts (pri-miRNA) (sized $>1 \mathrm{~kb}$ ) that undergo normal further processing i.e. 5'-capping $3^{\prime}$ - polyadenylation or even splicing [21]. However, miRNAs embedded in repetitive elements such as Alus can be transcribed by RNA polymerase III [22]. These RNA molecules form specific hairpin-shaped stem-loop secondary structures and enter a multi-enzyme complex known as a microprocessor to be modified by the RNAse III enzyme Drosha and its co-factor, Pasha. This process leads to the formation of a $\sim 70$ nt precursor miRNAs (premiRNA) with a $5^{\prime}$-phosphate and a $3^{\prime}-2$ nt long overhang [23]. Thereafter, ras-related nuclear protein (RAN-GTP) and exportin 5 mediate the export of pre-miRNAs from nucleus to cytoplasm [24]. Cytoplasmic pre-miRNAs are further processed by another RNAse III enzyme termed Dicer to generate a transient $\sim 22 \mathrm{nt}$ long double stranded miRNA [25]. This duplex is unwounded by helicases into two single strands, one of which is then loaded into the miRNA-associated multi-protein RNA-induced silencing complex (RISC) which includes the Argonaute proteins and induces gene silencing through mRNA cleavage, translational repression or deadenylation. The other strand, passenger strand, of duplex miRNA is degraded $[26,27]$ (Figure 1).

miRNAs are found in plants, animals, and other diverse eukaryotes as well as a number of DNA viruses where it negatively control the expression of target genes. In plants and C. elegans, suppression of transcription process was observed $[28,29]$. This suppression is not a complete shut out, but rather miRNAs are now revealed to fine tune / modulate the rate of mRNA. Though, a few different hypothesis have been given on the action of miRNAs, in general, miRISC with miRNA moves toward the target mRNA, and binds miRNA in the complementary region in the $3^{\prime}$ untranslated region ( $3^{\prime}$ UTR) to either terminate the translation or to lead to degradation of the mRNA to interfere with the gene expression [30,31]. Once the miRNA is bound to a completely complementary region of mRNA, like siRNA, mRNA gets degraded. However, miRNA mediated regulation does not require to have a perfect match with its target-binding region. Only, 7-base sequence between $2^{\text {nd }}$ and $8^{\text {th }}$ nucleotide from the $5^{\prime}$ end is called "seed region," and a complete match of the sequence is required. It is believed that the strength of the inhibition varies depending on the sequence but, how it is done at good balance yet to be revealed. A single miRNA may directly affect the expression of hundreds of proteins at once and several miRNAs can also target the same mRNA and result in enhanced translational inhibition [32]. The exact mechanisms of gene repression are still being elucidated, but there is evidence for translational initiation inhibition, translational elongation inhibition, premature translational termination, and co-translational protein degradation [33]. Moreover, these recent studies have introduced a paradigm shift in our understanding 


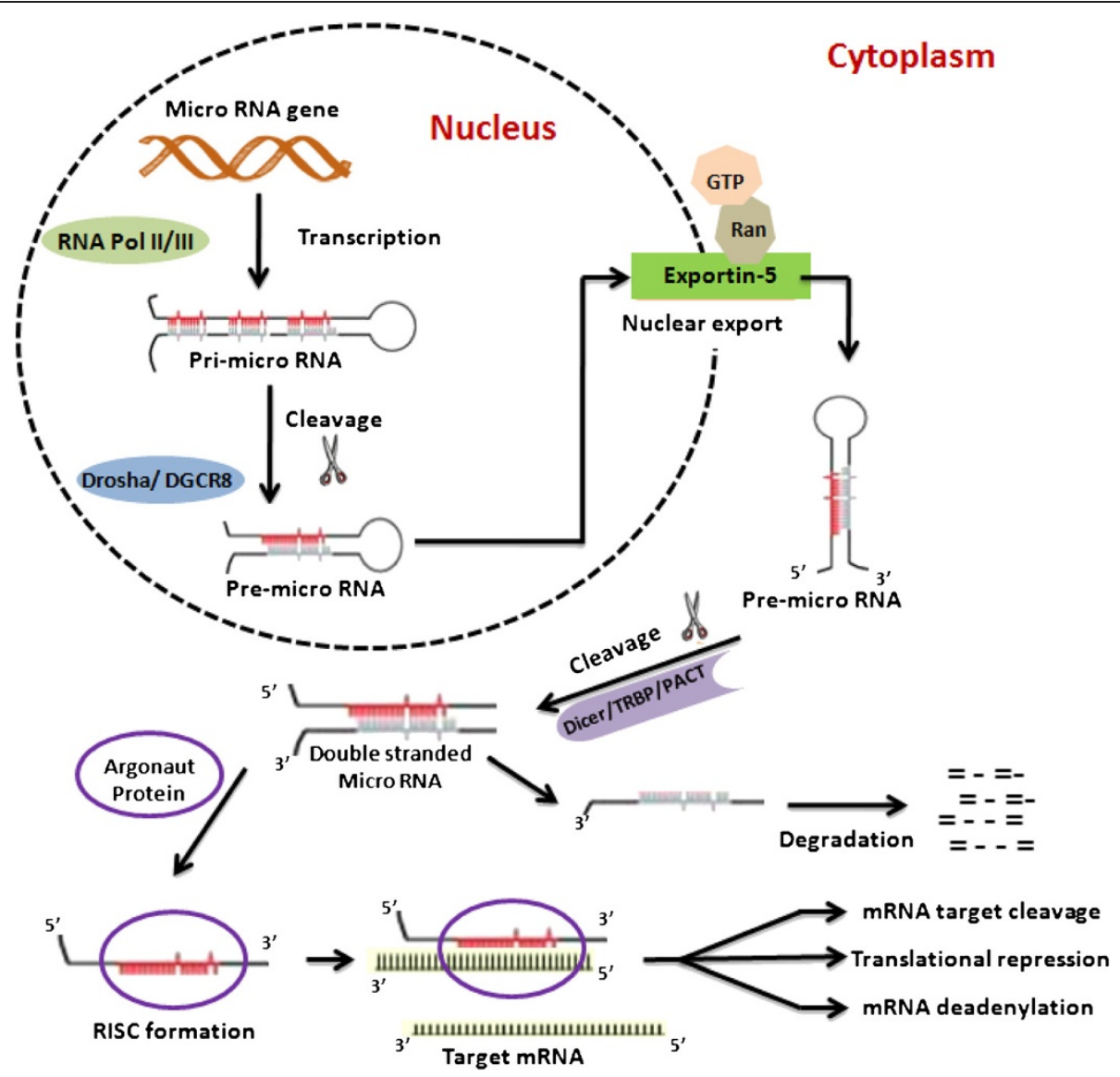

Figure 1 The linear synthetic pathway of micro-RNA biogenesis.

of the miRNA biogenesis pathway, which was previously believed to be universal to all miRNAs.

\section{miRNAs and its relation with bacterial infection}

Considering that more than 1,000 miRNAs have been so far annotated in the human genome and that individual miRNAs can have hundreds of targets, it has been predicted that roughly $60 \%$ of the human transcriptome may be regulated by miRNAs, although it remains unclear that how many of these are physiologically relevant targets [34]. The complex regulatory role of miRNA adds another layer to an already complex gene regulatory network involved in various biological processes as well as pathogenesis of diseases. There is increasing evidence suggesting that miRNAs play critical roles in many key biological processes, such as cell growth, tissue differentiation, cell proliferation, embryonic development, and apoptosis [35]. The most widely expanding, however, is the disease-related miRNA research based on miRNA expression analysis, probably due to the fact that generalized functional mechanisms were discovered for all miRNA. As per a manually curated, publicly available database (miR2disease.org), more than 150 human diseases (as viewed on Jan, 2013) have been documented to have relationship with miRNAs dysregulation [36]. Although, most of the evidences on involvement of microRNAs in diseases come from cancer research, the dysregulation of microRNAs has been associated with several other diseases viz., neurodegenerative, cardiovascular, pulmonary diseases, liver, kidney, brain and autoimmune diseases. In addition to well established function in physiological and pathological process, miRNAs are increasingly implicated in eukaryotic response to infectious pathogens. This area of research is now gaining the momentum to increase our understanding on complex biology of several infectious diseases.

With respect to infectious diseases, noticeable works was presented on miRNAs regulation in response to viruses and parasites. However, the role of miRNAs in bacterial infection is comparatively less explored area, but recent quantum jump discovered numerous miRNA regulation/ mis-regulation in response to a range of bacterial infections. The first report on role of miRNAs in bacterial infections was documented in plants where Arabidopsis miR-393 contributed to resistance against the extracellular bacteria Pseudomonas syringae, presumably by repressing 
auxin signalling [37]. After this first evidence, the regulations of mammalian miRNAs in response to bacterial infection are increasingly investigated. Helocobacter pylori is the main cause of peptic ulceration in human and gastric adenocarcinoma in human $[38,39]$. Currently, a study showed that H. pylori infections alter the expression of oncogenes, tumor suppressor genes and miRNAs [39]. Salmonella has been also found to significantly induce several miRNAs (like miR-155, miR-146a andmiR-21) [40]. Treatment of immune cells with bacterial lipopolysaccharide (LPS) from Salmonella and Escherichia coli led to the induction of miR-155, miR-132 and miR-146 expression [41]. The diverse miR-155 response to two subspecies of Francisella tularensis, a highly infectious Gramnegative bacterium that causes tularaemia has been reported [42]. Similarly to Gram-negative bacteria, Listeria monocytogenes (Gram-positive bacteria), also induce significant changes in the miRNA profile of bone marrowderived macrophages. Particularly, miR-155, miR-146a, miR-125a-3p/5p, and miR-149 all of which are implicated in regulation of immune related genes, were significantly induced [43]. The rapid progress in miRNA research has provided some concrete evidences on pivotal role of miRNAs in Mycobacterial diseases that are discussed below in detail.

miRNAs regulation in response to Mycobacterial infection The exact molecular pathogenesis of tuberculosis and other Mycobacterial diseases is not yet completely understood and this is one of the major hurdle in control of Mycobacterial disease especially Tuberculosis. The slow growth of Mycobacterium tuberculosis, coupled with many other quirks, make it a frustrating organism to deal with, while laboratory culture of the other major pathogen, Mycobacterium leprae (M. leprae), remains an elusive dream. Moreover, the tubercle bacillus has learnt how to defend itself against the existing drug regimens and the emergence of multi and extensive drug-resistant strains of $M$. tuberculosis is now a very real threat to world health. In general, intricate regulation of various eukaryotic/ host genes is crucial in the development of disease, and current understanding of miRNAs has unveiled a new layer of eukaryotic gene expression regulation unravelling several unsolved biological mechanisms in development or disease. This is why, now researchers are giving considerable attention to elucidate the relationship between miRNAs and Mycobacterial infection. Tables 1 and 2 summarize the available reports on the modulation of host miRNAs by some of studied Mycobacterium species.

miRNAs have been found in tissues and also in serum and plasma, and other body fluids, in a stable form that is protected from endogenous RNase activity (in association with RISC, either free in blood or in exosomes (endosome-derived organelles)). The potential for the use of these circulating miRNAs as biomarkers of disease and as targets of therapeutics is promising for various diseases especially cancer [44]. In view of potential significance of circulating miRNAs, the first success in clarification that miRNAs takes role in pulmonary tuberculosis pathogenesis was published in 2011 [45] in which

Table 1 Regulation of host micor-RNAs in response to Mycobacterial pathogens

\begin{tabular}{|c|c|c|c|c|}
\hline \multirow[t]{3}{*}{ Mycobacterium species } & \multirow{3}{*}{$\begin{array}{l}\text { Cells/samples and their source } \\
\text { Human monocyte derived macrophages }\end{array}$} & \multicolumn{2}{|c|}{ Regulated miRNAs } & \multirow{3}{*}{$\begin{array}{l}\text { Reference } \\
\text { Rajaram et al. [49] }\end{array}$} \\
\hline & & Up: & miR-125b & \\
\hline & & Down: & miR-155 & \\
\hline \multirow{6}{*}{$\begin{array}{l}\text { Mycobacterium tuberculosis } \\
\text { (M.tb) }\end{array}$} & PBMCs from TB patients & Up: & miR-144*, miR-155, miR-155* & Liu et al. [53] \\
\hline & & & & Wu et al. [50] \\
\hline & Serum from TB patients & Up: & miR-29a & Fu et al. [45] \\
\hline & Sputum from TB patients & Up: & miR-3179, miR-147, miR-29a & Yi et al. [46] \\
\hline & & Down: & miR-19b-2* & Fu et al. [45] \\
\hline & $\begin{array}{l}\text { M.tb infected bone marrow derived murine } \\
\text { macrophages }\end{array}$ & Up: & miR-155 & Kumar et al. [51] \\
\hline \multirow[t]{2}{*}{ Mycobacterium leprae } & Skin biopsy from Leprosy patients & Up: & miR-21 & Liu et al. [54] \\
\hline & PBMCs from Leprosy patients & Down: & mir-181a & Kumar et al. [56] \\
\hline \multirow[t]{2}{*}{ Mycobacterium bovis } & Murine T cells & Down: & $\operatorname{miR29}$ & Ma et al. [48] \\
\hline & & Up: & $\begin{array}{l}\text { miR-155, miR-146a/b, miR-886-5p, let-7e, } \\
\text { let-7i, miR-29a }\end{array}$ & Sharbati et al. [47] \\
\hline Mycobacterium avium & Human monocyte derived macrophages & Down: & $\begin{array}{l}\text { miR-20a, miR-191, miR-378, miR30c, miR- } \\
\text { 423-5p, } \\
\text { miR-374a, miR-185, miR-768-5p }\end{array}$ & \\
\hline Mycobacterium smegmatis & Human monocyte derived macrophages & Up: & miR-155 & Rajaram et al. [49] \\
\hline
\end{tabular}


Table 2 Identified micro-RNAs mediated modulation of host response during Mycobacterial infection/ stimulation

\begin{tabular}{lll}
\hline Micro-RNAs & Identified regulation mechanism & Reference \\
\hline miR-29 & Suppress the IFN- $\gamma$ production by targeting IFN- $\gamma$ mRNA & Ma et al. [48] \\
miR-29 and Let-7e & Inhibit the apoptosis by caspases 3 and 7 (major effector caspases) & Sharbati et al.[47] \\
miR 125b & Block the TNF-a biosynthesis & Rajaram et al. [49] \\
miR-155 & Enhance the TNF-a biosynthesis & Rajaram et al. [49] \\
miR-155 & Repress Bach1 and SHIP1 to support the dormancy and survival of $M$. tuberculosis in host & Kumar et al. [51] \\
miR-99b & Negatively regulate the production of proinflammatory cytokine that leads to reduced growth of $M$. & Singh et al, [50] \\
& tuberculosis & \\
\hline
\end{tabular}

the relationship between circulating serum miRNAs and active pulmonary tuberculosis was investigated by micro-array based expression profiling method. Among 92 miRNAs detected significantly, 59 miRNAs were downregulated and 33 miRNAs were upregulated in the TB serum compared to their levels in the control serum. Interestingly, on validating the micro-array results with real time PCR, differentially increased expression of miR29a and miR-93* was found not only in the serum but also in the sputum of patients with active pulmonary tuberculosis as compared to healthy controls [45]. After this first description, subsequently, genome wide miRNA expression in sputum supernatant of patients with active pulmonary tuberculosis was also delineated in recent past [46]. In this study, a total of 95 miRNAs were found to be expressed differentially by microarray and miR-3179, miR147 overexpressed and miR-19b-2* suppressed in TB patient group compared with controls as observed in the validation cohort by real time PCR.

In 2011, Sharbati and co-workers [47] demonstrated how distinct mycobacteria could manipulate host cell response by studying the regulatory network of potential interactions between miRNAs and mRNAs. The human macrophages infected with $M$. avium revealed that many of the differentially regulated miRNAs showed decreased expression (e.g., miR-20a, miR-191, miR-378, miR-185), whereas miR-155, miR-146a/b, miR-886-5p, miR-29a and let-7e were induced upon mycobacteria infection. The integrated analysis of miRNA and mRNA expression as well as target prediction and reporter assays identified caspases 3 and 7, major effector caspases essential in the triggering of apoptosis, as targets of let-7e and miR-29a, respectively, thus showing that inhibition of apoptosis after mycobacterial infection is controlled by miRNAs. The pivotal role of miR-29 was also demonstrated in $\mathrm{T}$ cells of mice infected with Listeria monocytogenes or Mycobacterium bovis bacillus CalmetteGuerin (BCG) [48]. However, in contrary to above observed induction of miR-29a, down-regulated expression of miR-29 in IFN- $\gamma$-producing natural killer cells, $\mathrm{CD}^{+} \mathrm{T}$ cells, and $\mathrm{CD}^{+} \mathrm{T}$ cells was observed. Interestingly, it was demonstrated that miR-29 directly target IFN- $\gamma$ mRNA and suppress the production of IFN- $\gamma$ [48].
Additionally, differential miRNA regulation was also reported recently in response to high virulent Mycobacteria (M. tuberculosis) as compared to low virulent (M. smegmatis) in infected human macrophages [49]. Macrophages incubated with surface molecule (lipomannan) of M.tuberculosis and live induce high miR-125b expression and low miR-155 expression with correspondingly low TNF production. Whereas, lipomannan of $M$. smegmatis and live induce high miR-155 expression and low miR-125b expression with high TNF production. The differential induction of TNF- $\alpha$ biosynthesis by the two mycobacteria species may be understood as; miR-125b directly targets the TNF- $\alpha$ mRNA, while miR-155 probably indirectly enhances TNF- $\alpha$ production by increasing TNF- $\alpha$ mRNA half-life and translation [41]. Therefore, high levels of miR-125b induced by $M$. tuberculosis, leads to the blocking of TNF biosynthesis, thereby allowing $M$. tuberculosis to subvert host immunity and potentially increase its virulence. In a very latest study, miR-99b mediated TNF- $\alpha$ modulation was also demonstrated that affects the bacterial growth in M. tuberculosis-infected dendritic cells [50]. Since, knockdown of miR-99b in dendritic cells associated with enhanced production of proinflammatory cytokines and significantly reduced bacterial growth, it will be interesting to explore further the potential of miR-99b to be used as therapeutics/ biomarker for tuberculosis. In a different study, higher expression of miR-155 and miR155* was observed in stimulated PBMCs (with tuberculin; antigen mixture of standard H37Rv strain of M.tuberculosis) of active tuberculosis patients as compared to unstimulated [51]. Therefore, tuberculin-induced increased expression of miR-155 and miR-155* explored its future exploitation as a diagnostic biomarker. However PPD is not considered a reliable stimulator, and it may trigger false-positive results in BCG-vaccinated or tuberculinpositive individuals. Very recently, specific secretory $M$. tuberculosis antigen, ESAT-6 was also found to play a key role in miR-155 induction and its subsequent effects on Bach1 and SHIP1 repression [52]. It is known that Bach1 is a transcriptional repressor of heme oxygenase-1 (HO-1; a documented activator of the M.tuberculosis dormancy), whereas SHIP1 inhibits the activation of the serine/threonine kinase AKT (required for M.tuberculosis survival). 
Therefore, it seems that miR-155 regulation is critical in modulation of host innate immunity and for protection against $M$. tuberculosis infection. M. bovis BCG was also found to trigger Toll-like receptor 2 (TLR2)-dependent miR-155 expression that takes part in mediating the apoptosis of macrophages through complex signaling pathways [53]. Thus it again suggested the importance of miR-155 and its role in orchestrating cellular reprogramming in response to Mycobacterial infection.

In addition to miR-155, the role of miR-144* precursor in modulation of anti-TB immunity through modification of cytokine production and cell proliferation of $\mathrm{T}$ cells was also demonstrated [54]. Besides, overexpression of miR-144* precursor in PBMCs of pulmonary tuberculosis cases, transfection of T cells with miR-144* precursor demonstrated that miR-144* might inhibit TNF- $\alpha$ and IFN- $\gamma$ production and $\mathrm{T}$ cell proliferation.

Recently, miRNA expression in leprosy skin lesions was also investigated in which 13 miRNAs were found to be expressed differentially in the lesions of human subjects with progressive lepromatous (L-lep) versus the self-limited tuberculoid (T-lep) disease [55]. mir-21, most differentially expressed miRNA in L-lep lesions was also overexpressed in M.leprae infected monocytes. Notably, it was also experimentally demonstrated that mir-21 inhibits the expression of the genes encoding two vitamin D-dependent antimicrobial peptides, CAMP and DEFB4A probably by direct downregualation of Toll-like receptor $2 / 1$ heterodimer (TLR2/1)-induced CYP27B1 and IL1B expression as well as indirectly upregulating interleukin-10 (IL-10). It is again noteworthy that knockdown of mir-21 in M. leprae-infected monocytes enhances the expression of CAMP and DEFB4A and restore TLR2/1-mediated antimicrobial activity against $M$. leprae. Therefore, study strongly suggests that mir-21 can potentially downregulate host defense genes (to escape from vitamin $\mathrm{D}$-dependent antimicrobial pathway) in leprosy. NF-kB activation mediated upregulation of miR-21 in response to Bacillus Calmette-Guerin (BCG) vaccination was also delineated in recent past [56]. Additionally, the role of miR-21 in suppression of IL-12 production (by targeting IL-12p35) and inducted dendritic cell apoptosis (by targeting Bcl-2) was mark out in BCG-vaccinated bone marrow derived macrophages. Therefore, this study again strengthened the role of miR-21 in fine-tuning of the antimycobacterial response in general and regulating the efficacy of BCG vaccination in particular. Besides the critical role of miR-21 in leprosy, miR-181a is another important RNA molecule which down-regulated expression may be associated with leprosy progression [57]. Furthermore, it was suggested that miR181a may contribute to overexpression of SHP2 that lead to T cell hyporesponsiveness during leprosy progression. Keeping all the above recent finding in notion, it is now clear that Mycobacteria can induce miRNA expression in immune cells and also miRNA plays important role both in progression as well as protection of Mycobacterial diseases.

\section{Role of miRNAs as biomarker and therapeutics in Mycobacterial diseases}

miRNA expression profiling is of increasing importance as it's exploitation in development of reliable diagnostic and prognostic biomarkers. In last few years, studies especially on role of miRNAs in different types of cancer have shown that miRNA expression profiles may classify the tumors and also it may potentially be used as biomarker for diagnosis and disease progression [58,59]. Encouraged with cancer studies, the role of miRNAs in infectious diseases including bacterial diseases was investigated. Although, some tantalizing evidences has been put forward on the possible role of miRNAs as biomarker for bacterial diseases including Mycobacterial infection, continued and extensive works however warranted in light of the marked global health impact of tuberculosis and problems associated with its diagnosis. As discussed in previous section, differential miRNA levels have been found in PBMCs [51,54], serum [45] and sputum [46] of TB patients as compared with healthy control. Of the various miRNAs, miR-29a, miR-155, miR-155*, miR-125b, miR-3179a and miR-147 may be of potential biomarker for diagnosis of tuberculosis (Table 1). Although, these miRNAs biomarkers have been identified by some independent groups but still it could not be validated adequately. Moreover, if we consider that these have potential to discriminate active and / or latent tuberculosis from healthy individuals, the question remains whether these gene expression signatures are specific for TB or shared, at least in part, with diseases of similar pathology but distinct etiology. This important issue was investigated in a recent study, in which whole blood miRNAs signatures of tuberculosis was compared with sarcoidosis that is known to have similar pathology [60]. This study showed significant differences in expression between healthy and diseased individuals, however, both $\mathrm{TB}$ and sarcoidosis revealed highly similar miRNAs profiles. The similarity of miRNAs profile may be due to the fact that miRNAs are primarily responsible for fine tuning of responses rather than on/off switch signals [61]. Therefore, on the basis of current understanding on this aspect, future works need on identifying the biomarkers by not only focusing on differential expression but also expression in diseases with similar pathology or diseases caused by closely related pathogens (like Mycobacterium species).

Besides use as a biomarker, another translational application of miRNAs has been explored as therapeutics. There are two main strategies for developing drugs targeting miRNA: (1) by suppressing the disease-specific miRNAs 
whose expression are increased in diseases and (2) by supplementing miRNA whose expression decreased. Tremendous efforts and progress are being made for the development of miRNAs based drugs especially for cancer [62] and Hepatitis $C$ virus infection [63]. The differentially expressed miRNAs found in response to Mycobacterial infection (Table 1) may have potential as future therapeutics however, no clinical trials and progress in this line have been made so far.

\section{Future direction: Expectation and limitation}

Despite of several advancement and rigorous research of last several decades, tuberculosis remains most deadly, major threat to mankind and an enigmatic infectious disease. Of the various research efforts in diverse directions for the control of tuberculosis, recently identified involvement of miRNA in mycobacterial infection has also nourished the hopes for better understanding of pathogenesis, developing new class of sensitive and accurate diagnostic and prognostic biomarkers and possible new therapeutics for tuberculosis. But currently this area is in its infancy and demanding more attention and continued works towards understanding the complex regulation of miRNA regulation in tuberculosis and further its exploitation to add the rational design for the effective control and management of tuberculosis. The accurate and rapid diagnosis as well as ability to monitor the treatment response is very crucial for effective control and management of tuberculosis. Although few miRNAs has been identified having ability to differentially diagnose the active TB and latent TB from healthy individuals $[45,64]$ but whether such biomarkers are of TB or shared by other diseases is yet not clear. Therefore, along with developing reliable miRNAs based biomarkers, future works are needed to discover biomarkers for the prediction of relapse, sterilizing activity and treatment response on account to provide batter treatment as well as to facilitate the testing of new drugs.

Recent landmark in- vitro and in-vivo studies in Mycobacterial diseases showed that miRNA species, regulating immune modulatory genes directly or indirectly, can affect the downstream effectors of an innate immune-triggered antimicrobial pathway $[48,54]$ and thereby contributing in development of disease. This knowledge may have implications for the development and improvement of future approaches for the prevention and therapy of tuberculosis. Since the identification of disease-specific miRNAs that cause the onset or exacerbation will lead to intellectual property as well as drug development, great efforts are made to research and develop them worldwide especially in cancer and a few other diseases. Although there are some successes and few miRNAs targeting drugs are currently under different phase of clinical trials, still suitable delivery system for miRNA drug and it's sustaining potency inside the body still need considerable attentions in future research. Recently, potential target sites of known human miRNAs were identified in M. tuberculosis genome by in-silico prediction method [65]. However, due to limitations of current miRNA target prediction programs, experimental validation of predicted miRNA targets is necessary to confirm. If host cell miRNAs are proven to play a role in regulating the intricate networks involved in human-M.tuberculosis interaction, it will open up a new area in both miRNA and $M$. tuberculosis research.

The limitation to applicability of miRNAs as biomarker and therapeutics reflected by the very basic and still unresolved question as to whether the increase or decrease of miRNA expressions actually cause the disease or if they are a consequence of the disease. Additionally, it is known that miRNAs contribute in various biological processes and single miRNA may modulate the expression of hundreds of genes therefore administration of miRNA as drug to cure any targeted disease, may lead to unwanted gene silence. Therefore, the above challenges should be kept in notion while taking the initiative for the development of miRNAs targeted/ based biomarkers or therapeutics for tuberculosis or other diseases. Overall, in future greater emphasize on basic research is needed simultaneous with research for translational application of miRNAs in mycobacterial diseases, especially in tuberculosis.

\section{Conclusions}

miRNAs represent a relatively young field of basic biological and translational research into new and innovative therapeutic applications. Tantalizing preliminary evidence, miRNAs have altered expression and are able to modulate the host antibacterial pathways in response to Mycobacterial infection, have created new opportunities in tuberculosis research. Since research on similar line begun only recently, the future research on identification and detail understanding of how host cell miRNAs regulate Mycobacterial infection will be of exquisite importance in view of development of novel biomarkers and therapeutics. The rapid advancement and explosion in miRNA research nourishes our hope for a giant leap in better diagnosis and treatment of infectious diseases including tuberculosis in future.

\section{Competing interests}

The authors declare that they have no competing interests.

\section{Authors' contributions}

PKS and DSC designed the concept. PKS and AVS collected information, and prepared the manuscript and figures. PKS and DSC wrote the final manuscript. All authors read and approved the final manuscript.

\section{Acknowledgment}

Indian Council of Medical Research (ICMR), New Delhi is greatly acknowledged for the award of 'Post Doctoral Fellowship' to P.K. Singh and A.V. Singh. 
Received: 8 January 2013 Accepted: 23 February 2013

Published: 28 February 2013

\section{References}

1. Bartel DP: MicroRNAs: genomics, biogenesis, mechanism, and function. Cell 2004, 116(2):281-297.

2. Lee RC, Feinbaum RL, Ambros V: The C. elegans heterochronic gene lin-4 encodes small RNAs with antisense complementarity to lin-14. Cell 1993, 75(5):843-854

3. Reinhart BJ, Slack FJ, Basson M, Pasquinelli AE, Bettinger JC, Rougvie AE, Horvitz HR, Ruvkun G: The 21-nucleotide let-7 RNA regulates developmental timing in Caenorhabditis elegans. Nature 2000, 403(6772): 901-906.

4. Ambros V: The functions of animal microRNAs. Nature 2004, 431(7006): 350-355.

5. Voinnet O: Induction and suppression of RNA silencing: insights from viral infections. Nat Rev Genet 2005, 6(3):206-220.

6. Taganov KD, Boldin MP, Baltimore D: MicroRNAs and immunity: tiny players in a big field. Immunity 2007, 26(2):133-137.

7. Ding SW, Voinnet O: Antiviral immunity directed by small RNAs. Cell 2007, 130(3):413-426.

8. Cullen BR: Viruses and microRNAs: RISCy interactions with serious consequences. Genes Dev 2011, 25(18):1881-1894.

9. Hakimi MA, Cannella D: Apicomplexan parasites and subversion of the host cell microRNA pathway. Trends Parasitol 2011, 27(11):481-486.

10. Eulalio A, Schulte $L N$, Vogel J: The mammalian microRNA response to bacterial infections. RNA Biol 2012, 9(10):742-750.

11. Corti M, Palmero D: Mycobacterium avium complex infection in HIV/AIDS patients. Expert Rev Anti Infect Ther 2008, 6(3):351-363.

12. World Health Organization: Global tuberculosis control report. Geneva: WHO; 2011.

13. World Health Organization: Global Tuberculosis Control report. Epidemiology, Strategy, Financing. Geneva: WHO; 2009

14. Rodriguez A, Griffiths-Jones S, Ashurst UL, Bradley A: Identification of mammalian microRNA host genes and transcription units. Genome Res 2004, 14(10A):1902-1910.

15. Kim NV, Jin-Wu N: Genomics of microRNA. Trends Genet 2006, 22(3):165-173.

16. Lee Y, Jeon K, Lee JT, Kim S, Kim VN: MicroRNA maturation: Stepwise processing and subcellular localization. EMBO J 2002, 21(17):4663-4670

17. Lagos-Quintana M, Rauhut $R$, Lendeckel $W$, Tuschl $T$ : Identification of novel genes coding for small expressed RNAs. Science 2001, 294(5543):853-858.

18. Mourelatos Z, Dostie J, Paushkin S, Sharma A, Charroux B, Abel L, Rappsilber J, Mann M, Dreyfuss G: A novel class of ribonucleo proteins containing numerous microRNAs. Genes Dev 2002, 16(6):720-728.

19. Lau NC, Lim LP, Weinstein EG, Bartel DP: An abundant class of tiny RNAs with probable regulatory roles in Caenorhabditis elegans. Science 2001, 294(5543):858-862

20. Lee Y, Kim M, Han J, Yeom KH, Lee S, Baek SH, Kim VN: MicroRNA genes are transcribed by RNA polymerase II. EMBO J 2004, 23(20):4051-4060.

21. Cai $X$, Hagedorn $C H$, Cullen BR: Human microRNAs are processed from capped, polyadenylated transcripts that can also function as mRNAs. RNA 2004, 10(12):1957-1966.

22. Borchert GM, Lanier W, Davidson BL: RNA polymerase III transcribes human microRNAs. Nat Struct Mol Biol 2006, 13(12):1097-1101.

23. Denli AM, Tops BB, Plasterk RH, Ketting RF, Hannon GJ: Processing of primary microRNAs by the Microprocessor complex. Nature 2004, 432(7014):231-235.

24. Bohnsack MT, Czaplinski K, Gorlich D: Exportin 5 is a RanGTP-dependent dsRNA-binding protein that mediates nuclear export of pre-miRNAs. RNA 2004, 10(2):185-191.

25. Hutvagner G, McLachlan J, Pasquinelli AE, Balint E, Tuschl T, Zamore PD: A cellular function for the RNA-interference enzyme Dicer in the maturation of the let-7 small temporal RNA. Science 2001, 293(5531):834-838.

26. Schwarz DS, Hutvagner G, Du T, Xu Z, Aronin N, Zamore PD: Asymmetry in the assembly of the RNAi enzyme complex. Cell 2003, 115(2):199-208.

27. Winter J, Jung S, Keller S, Gregory RI, Diederichs S: Many roads to maturity: microRNA biogenesis pathways and their regulation. Nature Cell Bio 2009, 11(3):208-234
28. Grishok A, Sinskey JL, Sharp PA: Transcriptional silencing of a transgene by RNAi in the soma of C. elegans. Genes Dev 2005, 19(6):683-696.

29. Baulcombe D: RNA silencing in plants. Nature 2004, 431(7006):356-363.

30. Lu R, Maduro M, Li F, Li HW, Broitman-Maduro G, Li WX, Ding SW: Animal virus replication and RNAi-mediated antiviral silencing in Caenorhabditis elegans. Nature 2005, 436(7053):1040-1043.

31. O' Donnell KA, Wentzel EA, Zeller KI, Dang CV, Mendell JT: c-Myc-regulated microRNAs modulate E2F1 expression. Nature 2005, 435(7043):839-843.

32. Selbach M, Schwanhausser B, Thierfelder N, Fang Z, Khanin R, Rajewsky N: Widespread changes in protein synthesis induced by microRNAs. Nature 2008, 455(7209):58-63.

33. Eulalio A, Huntzinger E, Izaurralde E: Getting to the root of miRNAmediated gene silencing. Cell 2008, 132(1):9-14.

34. Friedman JM, Jones PA: MicroRNAs: critical mediators of differentiation, development and disease. Swiss Med Wkly 2009, 139(33-34):466-472.

35. Esquela-Kerscher A, Slack FJ: Oncomirs - microRNAs with a role in cancer. Nat Rev Cancer 2006, 6(4):259-269.

36. Jiang $Q$, Wang $Y$, Hao $Y$, Juan $L$, Teng $M$, Zhang $X$, Li M, Wang G, Liu Y: miR2Disease: a manually curated database for microRNA deregulation in human disease. Nucleic Acids Res 2009, 37(Database issuue):D98-104.

37. Navarro L, Dunoyer P, Jay F, Arnold B, Dharmasiri N, Estelle M, Voinnet O, Jones JD: A plant miRNA contributes to antibacterial resistance by repressing auxin signaling. Science 2006, 312(5772):436-439.

38. Xiao J, Li Y, Wang K, Wen Z, Li M, Zhang L, et al: In silico method for systematic analysis of feature importance in microRNA-mRNA interactions. BMC Bioinforma 2009, 10:427.

39. De Flora S, Bonanni P: The prevention of infection-associated cancers. Carcinogenesis 2011, 32(6):787-795.

40. Schulte LN, Eulalio A, Mollenkopf HJ, Reinhardt R, Vogel J: Analysis of the host microRNA response to Salmonella uncovers the control of major cytokines by the let-7 family. EMBO J 2011, 30(10):1977-1989.

41. Tili E, Michaille JJ, Cimino A, Costinean S, Dumitru CD, Adair B, Fabbri M, Alder H, Liu CG, Calin GA, Croce CM: Modulation of miR-155 and miR$125 \mathrm{~b}$ levels following lipopolysaccharide/TNF-alpha stimulation and their possible roles in regulating the response to endotoxin shock. J Immunol 2007, 179(8):5082-5089.

42. Cremer TJ, Ravneberg DH, Clay CD, Piper-Hunter MG, Marsh CB, Elton TS, Gunn JS, Amer A, Kanneganti TD, Schlesinger LS, Butchar JP, Tridandapandi S: MiR-155 induction by F. novicida but not the virulent $F$. tularensis results in SHIP down-regulation and enhanced pro-inflammatory cytokine response. PLoS One 2009, 4(12):e8508.

43. Schnitger AK, Machova A, Mueller RU, Androulidaki A, Schermer B, Pasparakis M, Kronke M, Papadopoulou N: Listeria monocytogenes infection in macrophages induces vacuolar-dependent host miRNA response. PLoS One 2011, 6(11):e27435.

44. Jackson DB: Serum-based microRNAs: are we blinded by potential? Proc Natl Acad Sci USA 2009, 106(1):E5

45. Fu Y, Yi Z, Wu X, Li J, Xu F: Circulating microRNAs in patients with active pulmonary tuberculosis. J Clin Microbiol 2011, 49(12):4246-4251.

46. Yi Z, Fu Y, Ji R, Li R, Guan Z: Altered micro RNA signatures in sputum of patients with active pulmonary tuberculosis. PLoS One 2012, 7(8):e43184

47. Sharbati J, Lewin A, Kutz-Lohroff B, Kamal E, Einspanier R, Sharbati S: Integrated microRNA-mRNA-analysis of human monocyte derived macrophages upon Mycobacterium avium subsp. hominissuis infection. PLoS One 2011, 6(5):e20258

48. Ma F, Xu S, Liu X, Zhang Q, Xu X, Liu M, Hua M, Li N, Yao H, Cao X: The microRNA miR-29 controls innate and adaptive immune responses to intracellular bacterial infection by targeting interferon $\gamma$. Nat Immunol 2011, 12(9):861-869.

49. Rajaram MV, Ni B, Morris JD, Brooks MN, Carlson TK, Bakthavachalu B, Schoenberg DR, Torrelles JB, Schlesinger LS: Mycobacterium tuberculosis lipomannan blocks TNF biosynthesis by regulating macrophage MAPKactivated protein kinase 2 (MK2) and microRNA miR-125b. Proc Natl Acad Sci USA 2011, 108(42):17408-17413.

50. Singh Y, Kaul V, Mehra A, Chatterjee S, Tousif S, Dwivedi VP, Suar M, Kaer LV, Bishai WR, Das G: Mycobacterium tuberculosis controls miR-99b expression in infected murine dendritic cells to modulate host immunity. J Biol Chem 2012. Epub ahead of print

51. Wu J, Lu C, Diao N, Zhang S, Wang S, Wang F, Gao Y, Chen J, Shao L, Lu J, Zhang $X$, Weng $X$, Wang $H$, Zhang W, Huang $Y$ : Analysis of microRNA expression profiling identifies miR-155 and miR-155* as potential 
diagnostic markers for active tuberculosis: a preliminary study. Hum Immunol 2012, 73(1):31-37.

52. Kumar R, Halder P, Sahu SK, Kumar M, Kumari M, Jana K, Ghosh Z, Sharma P, Kundu M, Basu J: Identification of a novel role of ESAT-6-dependent miR155 induction during infection of macrophages with Mycobacterium tuberculosis. Cell Microbiol 2012, 14(10):1620-1631.

53. Ghorpade DS, Leyland R, Kurowska-Stolarska M, Patil SA, Balaji KN: MicroRNA-155 is required for Mycobacterium bovis BCG-mediated apoptosis of macrophages. Mol Cell Bio 2012, 32(12):2239-2253.

54. Liu Y, Wang X, Jiang J, Cao Z, Yang B, Cheng X: Modulation of T cell cytokine production bymiR-144* with elevated expression in patients with pulmonary tuberculosis. Mol Immunol 2011, 48(9-10):1084-90

55. Liu PT, Wheelwright M, Teles R, Komisopoulou E, Edfeldt K, Ferguson B, Mehta MD, Vazirnia A, Rea TH, Sarno EN, Graeber TG, Modlin RL: MicroRNA21 targets the vitamin D-dependent antimicrobial pathway in leprosy. Nat Med 2012, 18(2):267-273.

56. Wu Z, Lu H, Sheng J, Li L: Inductive microRNA-21 impairs antimycobacterial responses by targeting IL-12 and BCl-2. FEBS Lett 2012, 586(16):2459-2467.

57. Kumar S, Naqvi RA, Khanna N, Rao DN: Disruption of HLA-DR raft, deregulations of Lck-ZAP-70-Cbl-b cross-talk and miR181a towards T cell hyporesponsiveness in leprosy. Mol Immunol 2011, 48(9-10):1178-1190

58. Cho WC: OncomiRs: the discovery and progress of microRNAs in cancers. Mol Cancer 2007, 6:60

59. Zen $\mathrm{K}$, Zhang $\mathrm{CY}$ : Circulating microRNAs: a novel class of biomarkers to diagnose and monitor human cancers. Med Res Rev 2012, 32(2):326-348.

60. Maertzdorf J, Weiner J 3rd, Mollenkopf HJ, TB Network TBon, Bauer T, Prasse A, Muller-Quernheim J, Kaufmann SH: Common patterns and diseaserelated signatures in tuberculosis and sarcoidosis. Proc Natl Acad Sci USA 2012, 109(20):7853-7858.

61. O'Connell RM, Rao DS, Chaudhuri AA, Baltimore D: Physiological and pathological roles for microRNAs in the immune system. Nat Rev Immunol 2010, 10(2):111-122.

62. Takeshita F, Patrawala L, Osaki M, Takahashi RU, Yamamoto Y, Kosaka N, Kawamata N, Kelnar K, Bader AG, Brown D, Ochiya T: Systemic delivery of synthetic microRNA-16 inhibits the growth of metastatic prostate tumors via down regulation of multiple cell-cycle genes. Mol Ther 2010, 18(1): 181-187.

63. Lanford RE, Hildebrandt-Eriksen ES, Petri A, Persson R, Lindow M, Munk ME, Kauppinen S, Orum H: Therapeutic silencing of microRNA-122 in primates with chronic hepatitis C virus infection. Science 2010, 327(5962):198-201.

64. Wang C, Yang S, Sun G, Tang X, Lu S, Neyrolles O, Gao Q: Comparative miRNA Expression Profiles in Individuals with Latent and Active Tuberculosis. PLoS One 2011, 6(10):e25832.

65. Guo W, Li JT, Pan X, Wei L, Wu JY: Candidate Mycobacterium tuberculosis genes targeted by human microRNAs. Protein Cell 2010, 1(5):419-421.

doi:10.1186/1423-0127-20-14

Cite this article as: Singh et al:: Current understanding on micro RNAs and its regulation in response to Mycobacterial infections. Journal of Biomedical Science 2013 20:14.

\section{Submit your next manuscript to BioMed Central and take full advantage of:}

- Convenient online submission

- Thorough peer review

- No space constraints or color figure charges

- Immediate publication on acceptance

- Inclusion in PubMed, CAS, Scopus and Google Scholar

- Research which is freely available for redistribution

Submit your manuscript at www.biomedcentral.com/submit
C Biomed Central 